\title{
Experimental Study of Lead-acid Battery Remaining Capacity Measuring in Photovoltaic Energy Storage System
}

\author{
Xiaoju Yin ${ }^{1,2}$, Fengge Zhang ${ }^{1}$, Xiuping Wang ${ }^{2}$, Yonggang Jiao ${ }^{1}$, Zhenghe $\mathrm{Ju}^{2}$ \\ ${ }^{1}$ School of Electrical Engineering, Shenyang University of Technology, Shenyang, \\ 110870, China \\ ${ }^{2}$ School of Renewable Energy, Shenyang Institute of Engineering, Shenyang, \\ 110136, China \\ *Corresponding author: Insolyxj@163.com
}

\begin{abstract}
The combination of ampere-hour method and open-circuit voltage method in the photovoltaic measurement system is studied in this paper. In order to achieve the purpose of online measurement for remaining capacity, the influence of internal battery discharge and temperature on the battery capacity should be considered. The battery capacity decreases by the increasing charging times, and the increasing terminal voltage difference causes the inaccurate measurement of the capacity of battery. In this paper, two experimental measurement methods are employed, which are complementary to each other, to make the system measurement more accurate and extend the life of lead-acid batteries. If the charging process of photovoltaic system is unstable, an optimization of lead-acid battery applications in photovoltaic energy storage system is explored at the same time. Finally, an illustrative example is presented to demonstrate the effectiveness of the proposed measuring method.
\end{abstract}

Keywords: remaining capacity measuring, internal discharge, photovoltaic, battery life, temperature compensation

\section{Introduction}

In recent years, the battery has been widely used as backup power in the photovoltaic power supply system and the electric power communication with the application and development of solar energy storage system. The online measurement of the residual capacity of battery is closely related to the stability of the whole system. In the solar photovoltaic power supply system, the online measurement of the residual capacity of battery can provide the based energy diversion control of system. On the other hand, it can help users to evaluate the use of energy storage effectively and it also can be used to identify the bad battery to protect the other series of battery. Batteries are the main energy storage devices in the photovoltaic system.

A lot of experiments have been done to study the relationship between the residual capacity and the terminal voltage of lead-acid battery, the battery self-discharge, the battery cycle life and the change of the terminal voltage difference. The experiments revealed that the battery self-discharge has a strong impact on the residual capacity, when the battery charging times increases, the battery capacity decreases obviously. Also, the temperature is one of the factors to affect the battery capacity in the photovoltaic system, so the temperature compensation is designed.

There are two methods. One is to use UBT100-018-6ME (Germany Digatron company) Battery Tester and a lot of experiment data to analyze specific measurement Ewhen the battery charged and discharged, and to use the open-circuit voltage to measure the battery initial state. The other is to use ampere-hour method to measure the remaining capacity during the charge and discharge. In this paper, we contrasted the advantages and 
disadvantages of two methods, and made their respective advantages complementary to each other, and then achieved the optimization results. As for the self-discharge, $v_{a}, v_{b}$ are changed by the battery aging, different discharge currents, different battery power emitted problem, we did a lot of experiment, which provide valuable base for PV energy storage.

\section{Relations of Lead-acid Battery Terminal Voltage and Remaining Capacity}

The lead-acid battery remaining discharge capacity is very important to the normal operation of photovoltaic systems. We should estimate the remaining capacity of the battery accurately and arrange the electricity load reasonably to ensure the safe and reliable operation of photovoltaic system. There are many factors affect the actual remaining capacity of the lead-acid battery, such as battery discharge rate, the discharge system, termination voltage, temperature etc.

The linear relationship of open circuit voltage and remaining battery capacity (state of charge) [1] is shown in Figure 1.

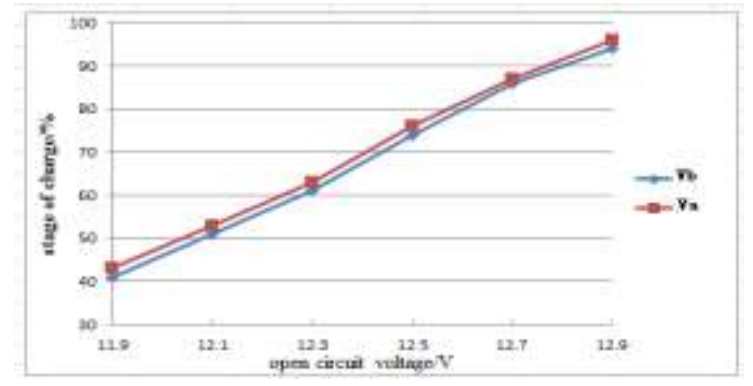

\section{Figure1 Relations of Remaining Capacity and Open Circuit Voltage in Valve-Regulated Lead-acid Batteries}

When lead-acid battery chemical reaction is stable, the open circuit voltage and remaining capacity have significant linear relationship, the ambient temperature and the battery aging factor have little effect on the linear relationship ${ }^{[2]}$, the relationship of the open circuit voltage and remaining capacity is shown in Eq. (1).

$$
\operatorname{soc}=\frac{v_{b o}-v_{a}}{v_{a}-v_{b}} \quad\left(v_{a}>v_{b o}>v_{b}\right)
$$

where $v_{a}$ is the open circuit voltage when the battery is fully charged for some time, $v_{b}$ is the open circuit voltage after fully discharge for some time, $v_{b o}$ is the open circuit voltage of the battery. When the three parameters are determined, the remaining capacity can be predicted. The battery should be standard which using the open-circuit voltage to measure remaining capacity and the $v_{a}, v_{b}$ will change by the battery aging.

\section{Research of the Remaining Capacity Prediction by Ampere-hour Method}

The basic theory of batteries is to integrate the charging and discharging current of initial state of the battery to get the remaining capacity [3]. As is shown in Eq. (2).

$$
\text { soc }=\operatorname{soc}_{0} \pm \frac{1}{C_{\text {full }}} \int_{t_{0}}^{t} i \mathrm{~d} \tau
$$

The ampere-hour method of testing circuit is easy to implement. However, this method is affected by temperature and the discharge current greatly. Temperature rising causes the maximum velocity of the electrolyte, which increases the electricity. Therefore, the 
penetration enhanced and the electrolyte resistance decreases, electrochemical reaction enhanced. All these make the battery capacity increases. When the maintenance-free lead-acid batteries charged under the oxygen cycle process, the additional heat will cause the battery temperature rising, exhibiting a greater temperature effect ${ }^{[4]}$, which is known ininitial battery state.

\section{Study on the Combination of Ampere-hour Method and Open- Circuit Voltage Method}

Based on the linear relationship of open circuit voltage and remaining battery capacity, the battery which stands for a period of time is imperfect. The ampere-hour method is easy to implement, but requiring the initial state characteristics. Then the combination of ampere-hour method and open-circuit voltage method are used to measure the remaining capacity of the battery online.

The specific measurement method is that during charging and discharging, the initial state of the battery is measured by the open-circuit voltage method, while the remaining capacity of the battery is measured by the ampere-hour method. But these two methods have their own advantages, and can complement respective advantages to each other, but the combination causes the problems such as self-discharge, $v_{a}$ and $v_{b}$ can be changed by the battery aging change, different discharge current and battery emitted different power. Finally, we have done a lot experiments to solve these problems.

\subsection{Study on the Influence of the Battery Self-discharge Measurement Method}

The internal chemical reaction will occur during the self-discharge, and which can reduce the battery capacity, thus the floating charged of battery is needed. Further, the system charging process may be interrupted shortly, but the standing time does not reach the requirement of open circuit voltage, when the battery charging and discharging process restarting, the system will use the record which before the break as the initial value state of the remaining capacity, and using the ampere-hour method continue to measure online, considering that the charging device stops working, the battery can produce self-discharge which caused the capacity before the interruption greater than the current value of the actual remaining capacity, which lead to inaccurate measurements and uncertainty floating charge problems.

Based on these characteristic curves of lead-acid batteries, many groups of battery and experimental data are analyzed to study the measurement methods by the battery selfdischarge, aimed to achieve the effective measure method, which make the measurement more accurate and close to the stable value. We did 60 hours of self-discharge test by $12 \mathrm{~V} / 40 \mathrm{AH}$ solar photovoltaic system batteries, which self-discharge voltage changes is shown in Figure 2.

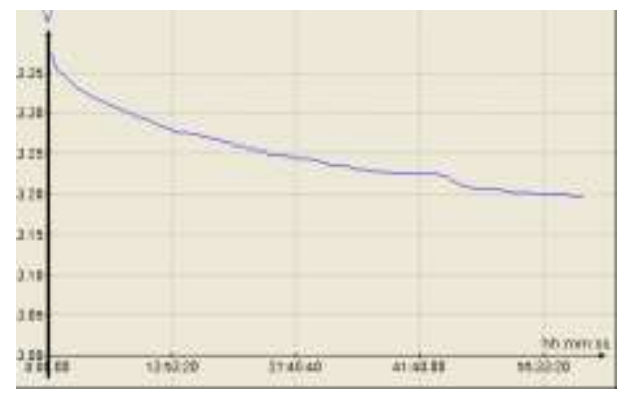

Figure 2. Battery self-discharge curve 


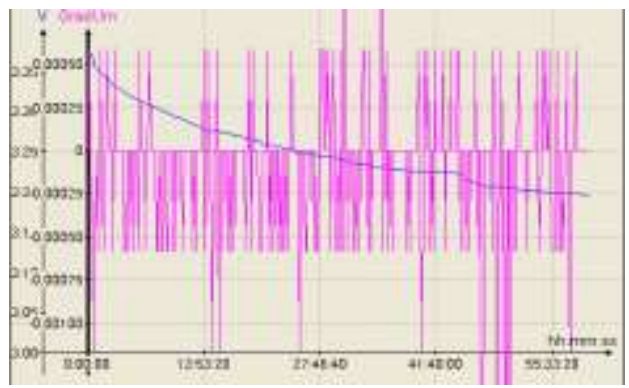

Figure 3. The Change Rate of Voltage of Battery Discharge

In Figure 2, the battery allowed to stand 60 hours, the battery terminal voltage dropped to $13.200 \mathrm{~V}$ from $13.375 \mathrm{~V}$ in the first two hours, and the voltage drop faster, which is the voltage drop when battery just stops charging, after two hours of stopping charging, battery is stabilized and the battery terminal voltage declines steadily in a straight line. This curve illustrates that the voltage downward trend is uniform when the battery is standing. In Figure 3, the rate of change of battery discharge voltage can also be seen, the rate $(\mathrm{du} / \mathrm{dt})$ tends to be a constant parameters $k_{1}$, and its value is negative, therefore:

$$
v_{b o}=k_{1} t+b
$$

The battery state of charge can be obtained by the Eqs. (1) and (3):

We define

$$
\text { soc }=\frac{k_{1}}{v_{a}-v_{b}} t+\frac{b-v_{b}}{v_{a}-v_{b}}
$$

$$
k_{2}=\frac{k_{1}}{v_{a}-v_{b}}
$$

From the above equation, the relation of battery state of charge and the standing time is a straight line with a slope of $k_{2} \cdot v_{a}$ is bigger than $v_{b}$, and the $k_{1}$ is negative, so $k_{2}$ is negative too. The battery state of charge decreases when the standing time uniformly increased.

In order to achieve a state before the standing, the battery was allowed to stand 60 hours. The total charge electricity is $0.03 \mathrm{AH}$. The self-discharge rate can be obtained:

$$
k_{2}=\frac{0.03 \mathrm{AH}}{60 \mathrm{H}}=\frac{1}{2000} \mathrm{AH} / \mathrm{H}
$$

The amount of self-discharge of the battery is $0.0005 \mathrm{AH}$ per hour, self-discharge capacity is $0.6 \mathrm{AH}$ every month. Thus, the battery self-discharge is very little, and has a little effect on ampere-hour method. Short stop charging or parking can be ignored also. When the battery reached required standing time, the initial state can be achieved by the open-circuit voltage method, for the $12 \mathrm{~V} / 40 \mathrm{AH}$ lead-acid batteries is full, $0.5 \mathrm{mAH}$ current to float charging can compensate the loss of self-discharge of the battery, other battery float current can be calculated based on their respective measured discharge curve.

\subsection{Study on the Changing for $v_{a}, v_{b}$ by Battery Aging}

4.2.1 Study on the Changing for $\boldsymbol{v}_{\boldsymbol{a}}$ by Battery Aging: The terminal voltage $v_{a}$ is gradually increased with the battery aging when the battery is full. We have done 18 times, 17 times, 31 times charge-discharge cycle test with two different brands of $12 \mathrm{~V} / 200 \mathrm{AH}$ new lead-acid batteries and $12 \mathrm{~V} / 38 \mathrm{AH}$ old lead-acid batteries, which is labeled by No. 1, No. 2 and No. 3 in the following analysis, which standing two hours after charging is completed. The results are as follows: 


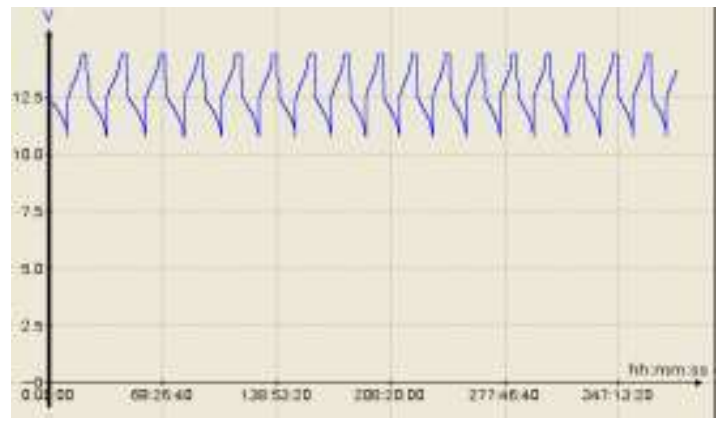

Figure 4. 18 Times Charge-discharge Cycles Voltage of 12V/200AH Leadacid Battery

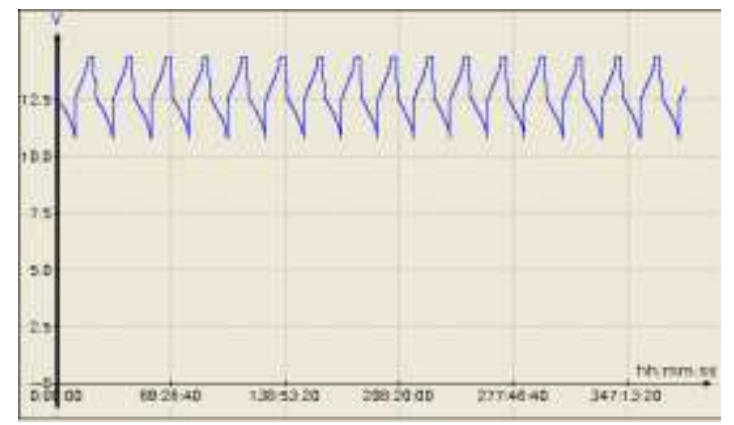

Figure 5. 17 Times Charge-discharge Cycles Voltage of 12V/200AH Leadacid Battery

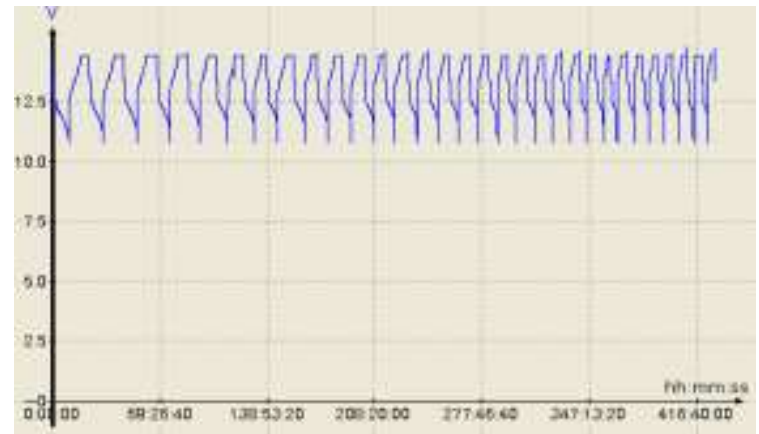

Figure 6. 31 Times Charge-discharge Cycles Voltage of 12V/38AH Lead-acid Battery

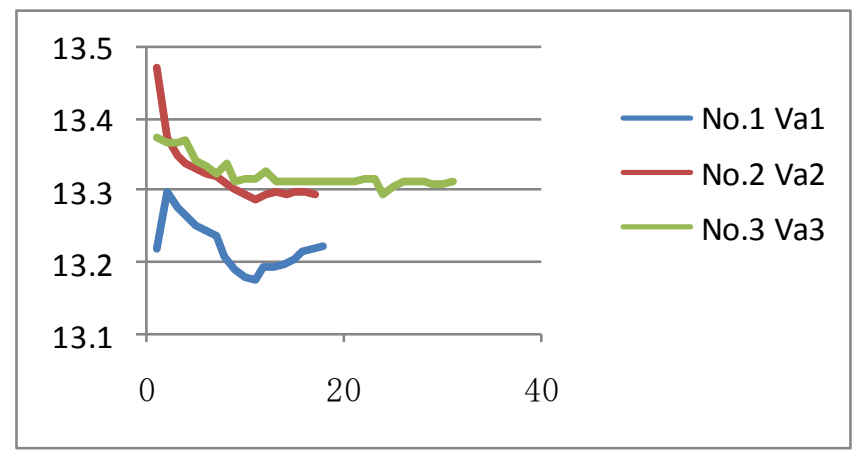

Figure 7. Trends of $v_{a}$ of Different Charge-discharge Times

Figure 4, Figure 5 and Figure 6 show the three groups of the battery voltage cycle test. Figure 7 is the trends of $v_{a}$ for different battery. As can be seen from the three group $v_{a}$ 
curves, $v_{a}$ decreases with the increased number of charge cycles. The 3rd experiment is the stage of aging, which can be seen from the experimental data. The charged battery is less than the rated capacity $(38 \mathrm{AH})$ of $80 \%$.

No. 1 , No. 2 is the new battery. It can be concluded that in the whole process of charge-discharge cycles, $v_{a}$ always shows the downward trend with the increase in the number of cycles.

Further, the initial values of Figure 7 and experimental data are removed (the terminal voltage is for the unknown standing time and it is impacted of internal changes and the self-discharge). In Figure 7 and Figure 8, the two curves are corresponding to strong correlation. The difference between the open circuit voltage in current state and the initial state is defined as open circuit voltage difference.

Ref. [5] pointed out: the greater difference of the internal battery resistance and the greater the open-circuit voltage, the worse of the health status of the battery.

If the external conditions such as temperature changed, $v_{a}$ is changed by the resistance of battery and the actual filled ampere hours.

As for the experimental data, removing the initial value, the average decline in the amount of battery of No. 1, No. 2 and No. 3 are $4.75 \mathrm{mV}, 5.13 \mathrm{mV}$ and $0.3 \mathrm{mV}$. The average rate of decline was $0.00036,0.00039$, and 0.00002 . As can be seen from these data, $v_{a}$ changes quite small with the battery aging.

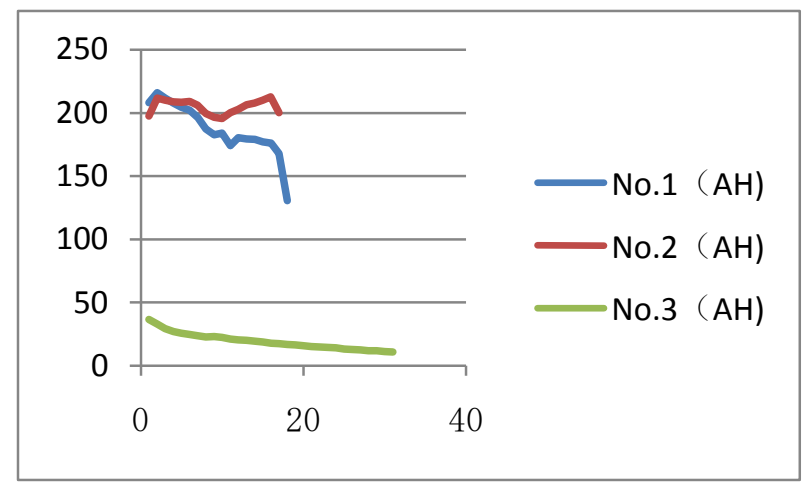

\section{Figure 8. Trends of Different Cycle Times of Different Ampere Hours}

4.2.2 Study on the Changing for $v_{b}$ by Charge-discharge Cycle Times: In order to obtain the terminal voltages changing trends based on the battery discharged fully with the number of the battery charging cycle's increasing and the battery aging. We test the $12 \mathrm{~V} / 17 \mathrm{AH}, 12 \mathrm{~V} / 75 \mathrm{AH}$ batteries for 50 and 46 times charge-discharge cycles to obtain $v_{b}$ of different number of cycles, and the battery need to stand for 2 hours after every discharge, the following experiments analysis are marked. In the 4th and the 5th, the experimental results are shown in Figure 9.

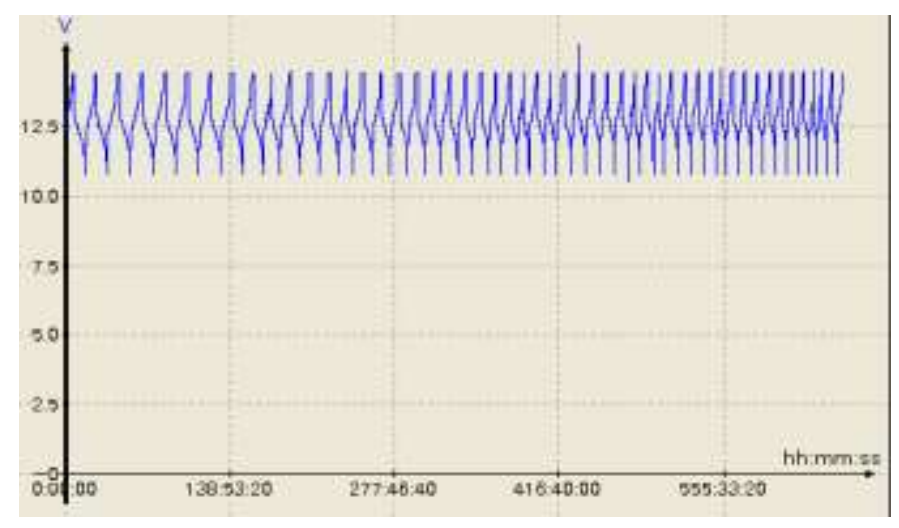


Figure 9. The Battery Voltage for 50 Cycles of $12 \mathrm{~V} / 17 \mathrm{AH}$

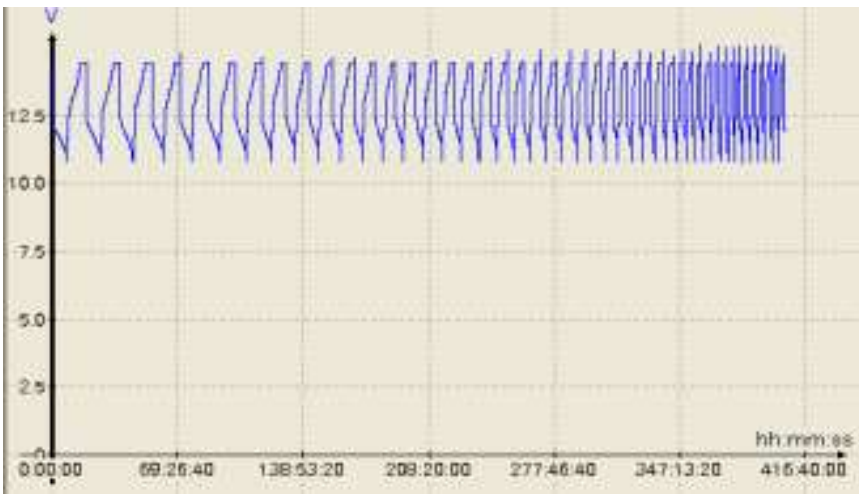

Figure 10. The Battery Voltage for 46 Cycles of $12 \mathrm{~V} / 75 \mathrm{AH}$

Table 1. The Values of $\boldsymbol{v}_{b}$ for Different Cycles

\begin{tabular}{|c|c|c|c|c|c|c|c|c|c|c|}
\hline count & 1 & 2 & 3 & 4 & 5 & 6 & 7 & 8 & 9 & 10 \\
\hline $\begin{array}{c}\text { No. } 4 \\
v_{b 1}\end{array}$ & 11.353 & 11.829 & 11.835 & 11.829 & 11.813 & 11.810 & 11.812 & 11.843 & 11.844 & 11.878 \\
\hline $\begin{array}{c}\text { No. 5 } \\
v_{b 2}\end{array}$ & 11.698 & 11.740 & 11.769 & 11.804 & 11.847 & 11.880 & 11.908 & 11.933 & 11.953 & 11.970 \\
\hline count & 11 & 12 & 13 & 14 & 15 & 16 & 17 & 18 & 19 & 20 \\
\hline $\begin{array}{c}\text { No. } 4 \\
v_{b 1}\end{array}$ & 11.889 & 11.905 & 11.926 & 11.963 & 11.956 & 11.969 & 11.986 & 12.005 & 12.033 & 12.035 \\
\hline $\begin{array}{c}\text { No. 5 } \\
v_{b 2}\end{array}$ & 11.990 & 12.010 & 12.023 & 12.041 & 12.049 & 12.068 & 12.083 & 12.099 & 12.115 & 12.125 \\
\hline count & 21 & 22 & 23 & 24 & 25 & 26 & 27 & 28 & 29 & 30 \\
\hline $\begin{array}{c}\text { No. 4 } \\
v_{b 1}\end{array}$ & 12.050 & 12.067 & 12.075 & 12.109 & 12.101 & 12.136 & 12.126 & 12.126 & 12.141 & 12.155 \\
\hline $\begin{array}{c}\text { No. 5 } \\
v_{b 2}\end{array}$ & 12.138 & 12.157 & 12.165 & 12.183 & 12.199 & 12.210 & 12.227 & 12.238 & 12.251 & 12.266 \\
\hline count & 31 & 32 & 33 & 34 & 35 & 36 & 37 & 38 & 39 & 40 \\
\hline $\begin{array}{c}\text { No. 4 } \\
v_{b 1}\end{array}$ & 12.168 & 12.170 & 12.186 & 12.203 & 12.205 & 12.237 & 12.224 & 12.247 & 12.280 & 12.283 \\
\hline $\begin{array}{c}\text { No. 5 } \\
v_{b 2}\end{array}$ & 12.290 & 12.318 & 12.344 & 12.385 & 12.375 & 12.391 & 12.412 & 12.416 & 12.425 & 12.423 \\
\hline count & 41 & 42 & 43 & 44 & 45 & 46 & 47 & 48 & 49 & 50 \\
\hline $\begin{array}{c}\text { No. 4 } \\
v_{b 1}\end{array}$ & 12.347 & 12.305 & 12.327 & 12.332 & 12.342 & 12.349 & 12.358 & 12.387 & 12.374 & 12.380 \\
\hline $\begin{array}{c}\text { No. 5 } \\
v_{b 2}\end{array}$ & 12.450 & 12.453 & 12.401 & 12.454 & 12.460 & 12.481 & 12.478 & 12.489 & 12.500 & 12.520 \\
\hline
\end{tabular}

Figure 9 and Figure 10 show the two groups of voltage during the test cycle. Table 1 shows the corresponding values of $v_{b}$. Figure 11 shows the trends of $v_{b}$ of different groups. In Figure 11, the values of $v_{b}$ increase with the increasing number of cycles, and closes to a straight line, it has been verified on gel batteries, the values of $v_{b}$ increase with the batteries aging, and the specific amount of change of each battery can be analyzed from Table 3 . The discharge current is the same since each cycle of the battery discharge cutoff, so the depth of discharge of the battery is the same. As the previous analysis, internal resistance increases with the number of cycles increasing. If other external conditions and the depth of discharge do not change, the changing values of $v_{b}$ are caused by the change of internal resistance. The average change of the battery between the 4th and 5th is $0.01157 \mathrm{~V}$ and $0.01841 \mathrm{~V}$, the average rate of change is $0.0009642 \mathrm{~V}$ and $0.001534 \mathrm{~V}$ respectively. 


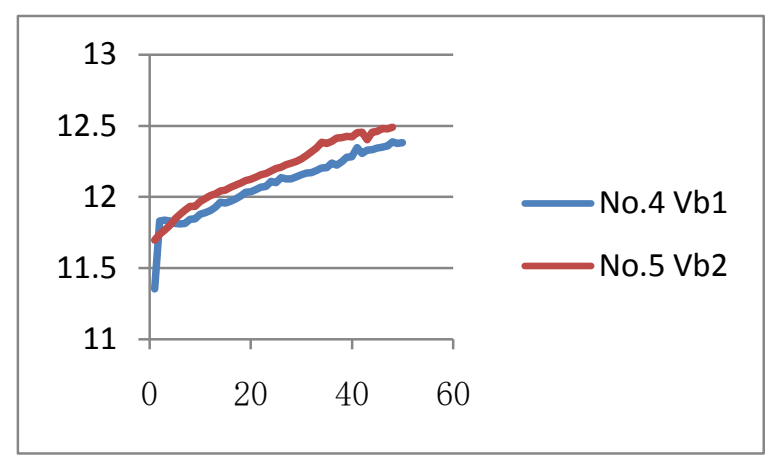

Figure 11. Trends of $v_{b}$ in Different Cycles

4.2.3 The Analysis of the Impact of Battery Aging on the Open Circuit Voltage Method in the Remaining Capacity Measuring: From the above results, $v_{a}$ is decreased while $v_{b}$ is increased with the increasing number of cycles. Substituting into (1) then it shows that: any terminal voltage $v_{b o}$ is increasing with the increasing number of cycles, but the state of charge is decreasing. So the corresponding terminal voltage increases with the increasing cycles at any state of charge. As the analysis of $v_{a}$ and $v_{b}$, when cycles are increasing and battery is aging, the effect is little. Experiments have validated this result.

To verify the influence on the state of charge of $v_{a}$ and $v_{b}$, charge and discharge experiments have done 18 times for $12 \mathrm{~V} / 65 \mathrm{AH}$ lead-acid batteries to take a different state of charge in each time. The battery was standing for 2 hours and the results are shown in Figure 12.

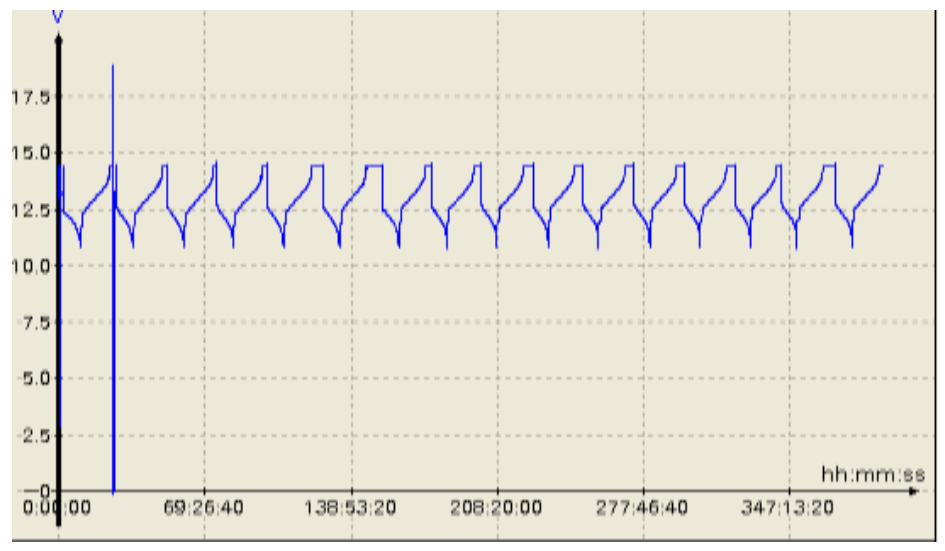

Figure 12. The Battery Voltage for 18 Cycles of $12 \mathrm{~V} / 65 \mathrm{AH}$

In the experiments, the battery had 18 times through the charge and discharge. Compared different terminal voltage corresponding to different remaining capacity, each trough in Figure 12 is a value corresponding to each $v_{b o}$, the specific $v_{b o}$ corresponding to the remaining capacity is shown in Figure 5.

Table 2. The Sampling Data of $12 \mathrm{~V} / 65 \mathrm{AH}$ Lead-acid Batteries Sampling Data

\begin{tabular}{|c|c|c|c|c|c|c|c|c|c|}
\hline Cycle time & 1 & 2 & 3 & 4 & 5 & 6 & 7 & 8 & 9 \\
\hline $\begin{array}{c}\text { Remaining } \\
\text { capacity }\end{array}$ & 62.219 & 9.555 & 62.683 & 8.97 & 9.447 & 12.25 & 10.667 & 14.189 & 17.512 \\
\hline$v_{b o}(\mathrm{~V})$ & 13.192 & 11.782 & 13.26 & 11.789 & 11.813 & 11.849 & 11.844 & 11.9 & 11.934 \\
\hline Cycle time & 10 & 11 & 12 & 13 & 14 & 15 & 16 & 17 & 18 \\
\hline Remaining & 18.122 & 19.638 & 21.167 & 21.802 & 22.642 & 23.799 & 24.997 & 25.81 & 24.798 \\
\hline
\end{tabular}




\begin{tabular}{|c|c|c|c|c|c|c|c|c|c|}
\hline capacity & & & & & & & & & \\
\hline$v_{b o}(\mathrm{~V})$ & 11.962 & 11.989 & 12.021 & 12.006 & 12.015 & 12.036 & 12.048 & 12.067 & 12.024 \\
\hline
\end{tabular}

The relationship curve of $v_{b o}$ and the remaining capacity can be analysis from Table 2 . As shown in Figure 13, if taking $v_{b o}$ and corresponded remaining capacity from different times, the difference is little, but the correspondence between $v_{b o}$ and the remaining capacity is still basically meet the correspondence between open voltage and remaining capacity as reference [1]. It can be concluded that aging on the battery has less impact on $v_{a}, v_{b}$ and $v_{b o}$, the open circuit voltage method is realistic and accurate in measuring the lead-acid battery.

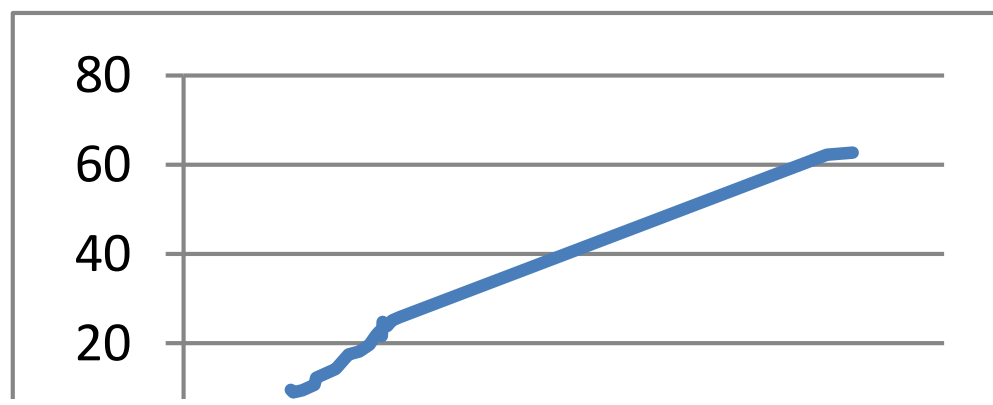

Figure 13. $v_{b o}$ of $12 \mathrm{~V} / 65 \mathrm{AH}$ Lead-acid Battery

\subsection{Relationship between Released Capacity and the Discharge Current}

The releasing capacity of the storage battery is different from the discharge current, and therefore the measurement system must be corrected.

It was found that the greater battery discharge rate, the less capacity emitted. Because the electrolyte cannot keep up with the proliferation of high-current discharge, when a small current discharge, the electrolyte has time to penetrate the plate and make the original active untapped inner the plate participate in the reaction, which release more capacity than the capacity of large current discharge. For this reason, we need to convert it to the standard output after comparing them, Ref. [6] defines a standard discharge current $I$, which emits a capacity of $C_{d s}$. By the Eq. (7), the current actually releases of electricity equivalent to capacity $C_{d z}$ of the released standard discharge current $I$. Thus, the measured value has a unified standard which can grasp the health of the battery by the battery charge state of online measurement, and solve the battery problem in time.

$$
C_{d z}(t)=\int_{t_{0}}^{t} \omega i_{d c h} \mathrm{~d} \tau
$$

where $\omega$ is weighting coefficients.

When the system charging method is determined, the value of $c_{\text {full }}$ of the new battery is determined, charging the battery to the off state to let the battery to be deep discharged in a standard discharged current, the total quantity of electricity discharged is $c_{f u l l}$, the formula of the state of battery charging process is:

$$
s o c=\operatorname{soc}_{0}+\frac{1}{C_{\text {full }}} \int_{t_{0}}^{t} i_{c h} \mathrm{~d} \tau
$$

The state of battery discharging process is:

$$
s o c=\operatorname{soc}_{0}-\frac{1}{C_{\text {full }}} \int_{t_{0}}^{t} i_{d c h} \mathrm{~d} \tau
$$

Ref. [6] proposed to use Peukert equation to calculate the value of $\omega$ :

$$
\omega=\frac{C_{d s}}{C_{i}}=\left[\frac{i_{d c h}}{I}\right]^{n-1}
$$


where $C_{i}$ is the discharge capacity when the battery discharge in $i_{d c h}, n$ is the battery model parameters. The 12V/40AH lead-acid batteries discharge experiment have verified the operability, it was found that the experimental data have large impact on the value of $n$. Table 3 is the characteristics of the battery discharge to $10.8 \mathrm{~V}$, and calculated the value of $n$ is in the standard discharge current of 4A.

\section{Table 3. The Value of $\boldsymbol{n}$ and the Battery Capacity in Different Discharge} Current

\begin{tabular}{|c|c|c|c|c|c|c|c|c|c|}
\hline Time & 39.926 & 11.983 & 8.193 & 6.297 & 4.918 & 4.074 & 3.546 & 3.150 & 2.833 \\
\hline Current(A) & 1 & 3 & 4 & 5 & 6 & 7 & 8 & 9 & 10 \\
\hline $\begin{array}{c}\text { Release } \\
\text { capacity }\end{array}$ & 39.926 & 35.950 & 32.77 & 31.487 & 29.509 & 28.516 & 29.368 & 28.351 & 28.326 \\
\hline$n$ & 1.149 & 1.325 & 1.180 & 1.258 & 1.290 & 1.208 & 1.556 & 1.157 & 1.159 \\
\hline
\end{tabular}

From the above cases, the $\mathrm{n}$ is not a certain value. Setting two data directly into the Peukert equation, the calculated value of $n$ as the general value is not accurate. Ref. [7] proposed a piecewise linear difference method to solve this problem: the value of $n$ in the standard discharge rate will be segmented, these points will be calculated into the computer table, then directly check the value of $n$ corresponding to the discharge current, the points can be calculated by the method of linear interpolation processing. The online calculate is not needed, and the value of $n$ do not change with battery aging, the data is accurate and operational.

\subsection{Temperature Compensation Design for Batter Measuring System}

The effect of temperature on the capacity represented by the following equation:

$$
C_{T}=C_{\text {full }}\left[1+\alpha_{t}(T-25)\right]
$$

Capacity of the battery increases with the electrolyte temperature, electrolyte temperature changes in the $10 \sim 35^{\circ} \mathrm{C}[4]$. When the temperature rises $1^{\circ} \mathrm{C}$, battery capacity increases $0.8 \%$. The value of $\alpha_{t}$ will be taken as $0.8 \%$ in the measurement system design. After discharge current and temperature correction, the measurement formula of the battery state of charge and discharge is:

$$
\begin{gathered}
S O C=\operatorname{soc}_{0}+\frac{1}{C_{\text {full }}[1+0.008(T-25)]} \int_{t_{0}}^{t} i_{c h} \mathrm{~d} \tau \\
S O C=\operatorname{soc}_{0}-\frac{1}{C_{\text {full }}[1+0.008(T-25)]} \int_{t_{0}}^{t}\left[\frac{i_{d c h}}{I}\right]^{n-1} i_{c h} \mathrm{~d} \tau
\end{gathered}
$$

According to the principle of the temperature transfer, placing the external sensors inside the shell of the battery before the location of the electrolyte to achieve the purpose of temperature measurement.

\section{Summary}

The method of terminal voltage and ampere-hour are used to measure the residual capacity of battery in the online measurement by a large number of photovoltaic energy storage experiments in this paper. The defect of the battery capacity will change with different discharge current and the temperature change can affect the measurement method, which has been carried on the correction. The terminal voltages changes will not affect the precision of the open circuit voltage; prediction charged state is validated by many times battery cycle experiments. The self-discharge test verifies the initial charged state in outage moment after short-term power cuts restarted. Ampere-hour method is 
reliability, and gives the specific data of float charging flow. These parameters provide reliable base for lead-acid battery energy storage in photovoltaic industry.

\section{References}

[1] M. P. Spiller and A. Jossen, Power Sources, vol. 96, no. 113, (2001).

[2] J. H. Aylo, A. Thieme and B. W. Johnso, IEEE Transactions, vol. 39, no. 398, (1992).

[3] C. B. Zhu, M. Coleman and W. G. Hurley, "State of Charge Determination in a Lead-acid Battery: Combined EMF Estimation and Ah-balance Approach", Power Electronics Specialists Conference, IEEE, PESC'04, vol. 1908, (2004).

[4] M. S. OuYang and S. J. Yu, Chinese Lab at Man, vol. 2, no. 59, (2004).

[5] Y. H. Xu, Chinese Labat Man, vol. 48, no. 279, (2011).

[6] G. G. Qi, J. M. Li, H. Jia and Y. M. Xu, Joumal of Tsinghua University(SciTech), vol. 37, no. 46, (1997).

[7] M. S. OuYang, "Study on the batteries management in standalone photovoltaic System", Hefei University of Technology, vol. 5, (2004).

[8] J. Eyer and G. Corey, "Energy Storage for the Electricity Grid", Sandia Nat'l Labs Publications [Online], (2010).

[9] N. Miller, D. Manz, J. Roedel, P. Marken and E. Kronbeck, "Utility Scale Battery Energy Storage Systems", IEEE Power Energy Soc. Gen. Meeting, (2010).

[10] J. Eyer and G. Corey, "Energy Storage for the Electricity Grid", Sandia Nat'l Labs Publications [Online], (2010).

[11] U. S. DOE, 20\% Wind Energy by 2030, (2008).

[12] P. Kundur, "Power System Stability and Control", New York: McGraw-Hill, vol. 589, (1994).

[13] "Energy Storage Association Technology", Comparisons [Online]. Available: http://www.Electricity storage.org/ESA/technologies/.

[14] C. Luo and B. T. Ooi, "Frequency Deviation of Thermal Power Plants due to Dind Farms", IEEE Trans on Energy Conversion, vol. 21, no. 708, (2006).

[15] S. J. W and O. Ryohei, "An Investigation on Optimal Battery Capacity in Wind Power Generation System", Tokyo: Waseda University, (2004).

[16] Q. Li, S. S. Choi and Y. Yuan, "On the Determination of Battery Energy Storage Capacity and Shortterm Power Dispatch of a Wind Farm", IEEE Trans on Sustainable Energy, vol. 2, no. 148, (2011).

[17] C. Abbey, K. Strunz and G. Joo, "A Knowledge-based Approach for Control of Two-level Energy Storage for Wind Energy Systems", IEEE Trans on Energy Conversion, vol. 2, no. 539, (2009).

[18] G. N. Bao, C. Lu and Z. C. Yuan, "Battery Energy Storage System Load Shifting Control based on Real Time Load Forecast and Dynamic Programming", IEEE International Conference on Automation Science and Engineering, vol. 815, (2012).
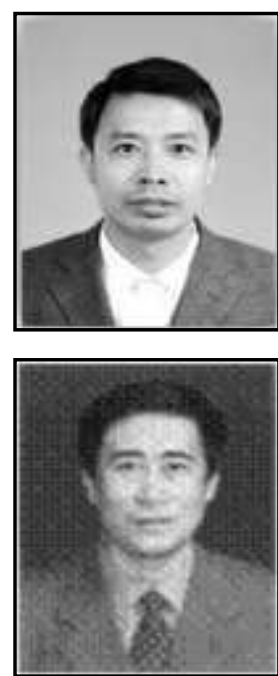

Copyright (C) 2015 SERSC

\section{Authors}

Xiaoju Yin, received the MBA degree from Liaoning University, Shenyang, China in 2007.

$\mathrm{He}$ is currently an associate professor with the School of Renewable Energy, Shenyang Institute of Engineering, and working towards the Ph.D degree in Electric Engineering in Shenyang University of Technology. His current research interests include the energy storage technology and intelligent control theory.

Fengge Zhang, received the Ph.D degree in Electrical Engineering from Shenyang University of Technology, Shenyang, China, in 2000. 
$\mathrm{He}$ is currently a professor with the College of Electrical Engineering, Shenyang University of Technology. His research interests include electromagnetic theory, optimized design for power converter etc.

Xiuping Wang, received the Ph.D degree in Electrical Engineering from Shenyang University of Technology, Shenyang, China, in 2014.

$\mathrm{He}$ is currently a lecturer with the School of Electric Power, Shenyang Institute of Engineering, Shenyang. His current research interests include electric magnetic theory, special electrical machine and its control technology.

Yonggang Jiao, received the B.E. degree in Electrical

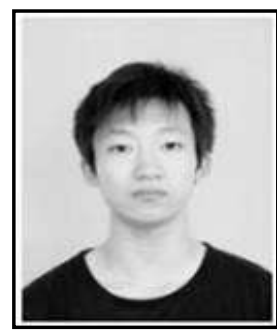

Engineering and Automation from Shenyang University of Technology, Shenyang, China in 2012.

$\mathrm{He}$ is currently working towards the Master degree in Electric Engineering in Shenyang University of Technology.

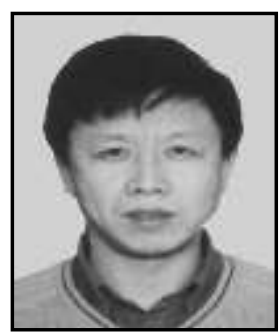

Zhenhe Ju, received the Master degree in Solar Engineering from Europe Solar Research Centre, Stockholm, Sweden, in 2004.

$\mathrm{He}$ is currently a professor with the School of Renewable Energy, Shenyang Institute of Engineering, Shenyang. His current research interests include solar photovoltaic application technology and green lighting technology, etc. 